\title{
STUDENT-PERCEIVED EPISTEMIC AUTHORITY OF ASSOCIATE PROFESSORS IN INSTITUTIONS OF HIGHER EDUCATION
}

\begin{abstract}
The article analyses the topical social epistemology issue of transmission and sharing of knowledge in the context of social psychology. Essential is focusing on authority as an attitude and, within this context, also focusing on an analysis of the structure of authority, situational structuring of authority.

Therefore, the aim of the study is to explore the epistemic authority of associate professors in institutions of higher education as perceived by the students of various study areas.

The concept of epistemic authority has been used to pursue the aim (Raviv, Bar-Tal, Ravi \& Abin, 1993; Kruglanski, 1989; Hepburn, 2006; Asmuß \& Svennevig, 2009; Glenn \& LeBaron, 2011). Exploring epistemic authority is related to exploring the degree of trust in epistemic authority (Kruglanski et al., 2005).

An epistemic authority study methodology including three interrelated surveys has been used in the study (Raviv, Bar-Tal, Raviv \& Abin, 1993).

The study sample consisted of students of various institutions of higher education in Riga $(N=307)$. The article analyses the results of the descriptive statistics of student-perceived epistemic authority of associate professors; statistically significant differences between the evaluations given by students of various areas for their perception of the epistemic authority of associate professors.

The article includes key conclusions which show that students rate the epistemic authority of associate professors as medium high, it is comparatively higher in the cognitive aspect-evaluation of the authority's level of knowledge and the cognitively emotional, i.e., trust in knowledge. The students have given a lower rating to the epistemic authority of associate professors in the cognitive behaviour aspect.
\end{abstract}

Keywords: epistemic authority; epistemic beliefs; perceived authority; students, professors

\section{INTRODUCTION}

Researchers of the constructive sociology of knowledge (Subramaniam, 2010; Miettinen \& Virkkunen, 2005) believe that, in the contemporary knowledge society, the construction of epistemic objects or cognitive objects (i.e., also social issues) is becoming more and more essential in the work of any expert. Therefore, the concept of epistemic authority has become topical in the context of authority studies. In accordance with philosopher R. Rorty's (Rorty, 1980; in Hepburn, 2006) opinion about the role of epistemology in the interpretation of social processes it is used in a wide discourse of science and cultural processes. An idea is developed about the influence of institutionally supported and legal professional power (Fuko, 2001), and the educational institution may therefore be perceived as a mechanism for putting into practice and realisation of power in the society. The authority of a pedagogue in the formal educational processes is believed to be one of the most important aspects of the problem of personal authority 
(Kruglanski et al., 2005; Pounder, 2008; Chiang, 2009; Patchen \& Crawford, 2011). Scientists emphasise the influences of the perceived control on the health and feeling of comfort of people and try to identify the determining factors of such perception (Goodman, 2010; Harjunen, 2009). Essential is focusing on authority as an attitude and, within this context, also focusing on an analysis of the structure of authority (Harjunen, 2009). Among many studies social epistemology issues with regard to transmission and acceptance of knowledge (Asmuß \& Svennevig, 2009), one of the issues relates to the influence of epistemic authority in the university (Guimond, 2001).

Therefore, the theory of social epistemology has become topical in the research of transmission and sharing of knowledge (Jacobson, 2007; Glenn, LeBaron, 2011), which requires research of trust in and reliance on pistemic authority, credibility of various persons (Kruglanski, 1989; Kruglanski et al., 2005).

Using the approach as the basis is also topical: A different set of issues may arise in the research of the situational determinants of epistemic authority ascriptions. Social cognition researchers have been emphasizing how people's attitudes, judgments and beliefs may be situationally constructed (Kruglanski et al., 2005). In so far as epistemic authority ascriptions also constitute beliefs, they too, should be susceptible to various situational influences.

\section{THE AIM OF THE STUDY}

To explore the epistemic authority of associate professors as perceived by the students of various study areas and to determine statistically significant differences in the evaluations given for epistemic authority of the associate professor by students in various study areas.

\section{MATERIALS AND METHODS}

Conceptually, the methodological basis of the study is practical epistemy or social epistemology (Jacobson, 2007). This means that, from a wider point of view, the research of the epistemic authority of associate professors means the research of the views of students regarding acquisition and transmission of knowledge and its effects on the functioning of students in the academic environment (Heritage \& Raymond, 2005). The students' individual epistemology is researched in such context (Ricco, Schuyten Pierce \& Medinilla, 2010), and, therefore, from a wider point of view, the idea of the study relates to the development of students' competence; the question asked: what part of students' knowledge depends on the influence of associate professors, i. e., a competent source of knowledge? (Mugny, Chatard \& Quiamzade, 2006; Quiamzade, Mugny \& Chatard, 2009).

Epistemic authority is defined as a source of information having the decisive influence on the formation of knowledge, and its acknowledgement relates to the reasons for reliance on the epistemic authority (Kruglanski, 1989; Kruglanski et al., 2005). In social psychology, the concept of epistemic authority is researched in the context of the concept of social judgements (Kruglanski et al., 2005; Rupp, 2011) in relation with social comparison: competence and self-competence of the epistemic authority and the accordingly developing degree of epistemic dependency (Kruglanski, 1989; Mugny, Chatard \& Quiamzade, 2006; Quiamzade, Mugny \& Chatard, 2009). Epistemic authority is associated with the efficiency of making social decisions (Kruglanski et al., 2005). In such context, researchers explore social views, beliefs (they are also defined as epistemological) (Bar-Tal, Raviv, Raviv \& Brosh, 1991), and such research is associated with an explanation of perception and interpretation of information (Ward \& Parr, 2006).

The methodological basis of the study also includes the concept of formation, also construction, of authority in discourse psychology (Hepburn, 2006), relying on the concept of mental representations. In this context, the author conceptually researches the results/consequences 
of the interaction between the student and the associate professor and the construction of knowledge in the interaction in the academic environment.

Therefore, the study methodology should also include the ideas of transition from the model of general transmission of knowledge - a logical one-way flow of information from the creators of knowledge to the users of knowledge - to more interactive models (Mahrous \& Ahmed Anis, 2010), where transmission of knowledge is a bilateral process of creation and application of knowledge (Jillapalli \& Wilcox, 2010). This implies a necessity to identify the types of possible evaluations of the expert's (i. e., the epistemic authority - associate professor) statements as substantiated true views (Bozalek \& Matthews, 2009; Mugny, Chatard \& Quiamzade, 2006; Quiamzade, Mugny \& Chatard, 2009). This applies to the process of getting evidence and the types of evidence offered to make judgements about the truth - the value of the experts' statements. One of the types is the so-called third party evaluation, which, in the context of the research conducted by the author, is the evaluation given by the students for the epistemic authority of the associate professors.

In the models of epistemological or epistemic views (Schommer-Aikins, 2004), evaluation of epistemic views has been developed, including also the dimension of ,reliance on the authority". This dimension relates to the view that other authorities (i. e., also associate professors) may be perceived uncritically as significant sources of knowledge. The study includes two principal questions: 1) what is epistemic authority in a specific area of knowledge; 2) what is the basic justification for the choice of the epistemic authority (Raviv, Raviv, Bar-Tal \& Peleg, 1990).

In such context, research of epistemic authority means finding out the degree to which an individual's claims for the role of an expert are accepted by another person (Raviv, Bar-Tal et al., 2003), i. e., the degree to which the student accepts the justification for the knowledge provided by the associate professor. Research of student-perceived epistemic authority of associate professors allows to estimate the evaluation of the omniscate authority (Schommer-Aikins, 2004), i. e, whether the knowledge has been transmitted (transferred) by experts (i.e., also associate professors) or acquired from individual judgements and observations of empirical observations. Empirically, this concept (Schommer-Aikins, 2004) is verified by studying also the epistemological views of students (Ordonez, Ponsoda, Abad, Romero, 2009).

A significant aspect in the methodology of the study is the so-called domain specifics deduced by researchers (Buehl \& Alexander, 2005) - students' views about the knowledge which influences behaviour; also different in various academic domains. This is also proved by a study on the perception of epistemic authority among students with regard to various areas: the students chose various epistemic authorities in various areas (Bar-Tal, Raviv, Raviv, Brosh, 1991). Therefore, the sample of the study conducted by the author included students from various study areas.

The methodology of researching epistemic authority includes three interrelated surveys. Epistemic Authority Scale (Raviv, Bar-Tal, Raviv \& Abin, 1993). This scale was used to study the level of epistemic authority of one associate professor chosen by students and graduates on a scale between 1 - disagree entirely to 6 - agree entirely. The responses to the 17 statements showed four topics in an increasing sequence: 1) the level of knowledge attributed to the associate professor by the student; 2) the level of student's trust in the knowledge of the associate professor; 3 ) the level of student's readiness to change their opinion; 4)the level of student's readiness to change their behaviour. 
Reliance Question (Raviv, Bar-Tal, Raviv \& Abin, 1993). Reasoning Questionnaire. This questionnaire was used to study the reasons for the reliance of the students and graduates on the perceived epistemic authority of the same one associate professor. Correspondence of these reasons to this associate professor was evaluated. Reasoning Questionnaire (Raviv, Bar-Tal, Raviv \& Abin, 1993). This questionnaire was used to determine the degree of the influence of the reason for the reliance based on which reason is or is not acknowledged as a reason for reliance on the information (knowledge) provided by the associate professor, i.e., epistemic authority.

\section{RESULTS}

In the group of students, the Cronbach's Alpha for all 17 statements in the Epistemic Authority Scale was $>.83$, which can be defined as a good validity index.

The research sample consisted of students from various institutions of higher education in Riga ( $\mathrm{N}=307)$, including: 101 - social area; 101 - the arts; 105 - the sciences. The results were obtained to answer the research questions: 1) what is the degree of evaluation of student-perceived epistemic authority in groups of study areas; 2) are there statistically significant differences in the evaluations of the epistemic authority of the associate professors perceived by students of various study areas.

Descriptive statistics results showed that the following tendency can be observed: cognitive aspect has higher results $(\mathrm{M}=4.78)$, which can be interpreted as medium high (maximal possible $\mathrm{M}=6.0$ ) - authority knowledge level evaluation, slightly lower - cognitive emotional that is, trust

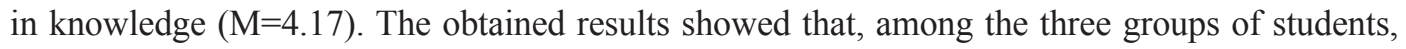
significant differences existed only on scale "Readiness to change opinion" $(\mathrm{p}=.014)$. A result relatively close to the statistically significant threshold value $\mathrm{p}=.05(\mathrm{p}=.077)$ was on the scale "Level of knowledge". No statistically significant differences were observed on the remaining three scales - "Trust in knowledge", "Readiness to change behaviour", and "Average total". The analysis of students' reliance on the epistemic authority primarily included finding out their opinions about whether they consider the associate professor an authority based on the reasons for the reliance on the associate professor. The results showed that the groups of students in all areas had a tendency to acknowledge the associate professor as an authority because he/she has opinions the students accept (considered to be so by 291 out of the 307 students), that the associate professor is an expert in their area of knowledge and experience (287 out of the 307 students), that the associate professor is impartial (255 out of the 307 students). In the acknowledgement of authority, this tendency was found less in the evaluation of the following reasons for the reliance: knowing personally (51 out of the 307 students), taking the acknowledgement of the influence over from others (54 out of the 307 students), association - the associate professor remind someone the student trusts ( 88 out of the 307 students).

An analysis of the degree to which the acknowledgement of the associate professor's authority influences the students' judgements in favour or against reliance on the information (knowledge) provided by the associate professor showed that the reliance was medium low. The arithmetic mean in the evaluation of the reasons for the reliance varied between $\mathrm{M}=1.56$ (I know (do not know) him/her personally) and $\mathrm{M}=2.76$ (He/she is (is not) expert: well educated or experienced) to total to the average value of $\mathrm{M}=2.19$ (the maximum possible would be $\mathrm{M}=6.0$ ) for the entire study. The following evaluations of the influence were also higher: He/she is (is not) impartial; He/she has (does not have) opinions I accept; He/she has (does not have) character traits significant to me. A low acknowledgement of the influence was found also for the following evaluations of the influence: transfer of acknowledgement of the influence - the 
associate professor influences (does not influence because he/she has influenced someone the student trusts; association - the associate professor reminds someone the student trusts.

Thereby, the influence of the associate professor's authority is more related to cognitive and cognitively emotional aspects. In the groups of students in the three areas (social, the arts, and the sciences), statistically significant differences in the results of the reliance questionnaire were found in the evaluation of the influence of impartiality $(p=.046)$ - a stronger influence of impartiality was acknowledged by students of the arts. Statistically significant differences were also found in the evaluation of the associate professor's interest in student's feeling of comfort as a reason for reliance $(\mathrm{p}=.005)$ - this influence was considered to be less significant by the students of the sciences. The differences in the evaluation of the reason for influence "I feel (do not feel) that I can trust him/her" ( $p=.015)$ were also significant. This influence was considered to be more significant by the students of the arts.

\section{CONCLUSIONS}

Students rate the epistemic authority of associate professors in institutions of higher education as medium high, it is comparatively higher in the cognitive aspect - evaluation of the authority's level of knowledge and the cognitively emotional, i.e., trust in knowledge. The students have given a lower rating to the epistemic authority of associate professors in the cognitive behaviour aspect - readiness to change the opinion and behaviour under the influence of the authority of the associate professor. During the study, differences were found in the evaluations given for the epistemic authority of associate professors and reliance on epistemic authority by students of various areas. The main reasons why the students acknowledge the associate professor as an epistemic authority include the fact that the associate professor has opinions the student accepts, the associate professor's ability to be an expert - knowledgeable and experienced in their professional area, and impartiality of the associate professor.

\section{REFERENCES}

Asmuß, B., \& Svennevig, J. (2009). Meeting talk: An introduction. Journal of Business Communication, 46, $3-22$.

Bar-Tal, D., Raviv, A., Raviv, A. \& Brosh, M. (1991). Perception of epistemic authority and attribution for its choice as a function of knowledge area and age. European Journal of Social Psychology, 21, 477492.

Bozalek, V. \& Matthews, L. (2009). E-learning: A cross-institutional forum for sharing socio-cultural influences on personal and professional identity. International Social Work, 52, 235-246.

Buehl, M. M. \& Alexander, A. P. (2005). Motivation and performance differences in students' domain-specific epistemological belief profiles. American Educational Research Journal, 42(4), 697-726.

Chiang, S. Y. (2009). Personal power and positional power in a power-full 'I': A discourse analysis of doctoral dissertation supervision. Discourse \& Communication, 3(3), 255-271.

Fuko, M. (2001). Uzraudzìt un sodìt [Discipline and punish: the birth of the prison]. Rìga: Omnia mae. (in Latvian).

Glenn, P., \& LeBaron, C. (2011). Epistemic authority in employment interviews: Glancing, pointing, touching. Discourse \& Communication, 5(1), 3-22.

Goodman, J. (2010). Student authority: Antidote to alienation. Theory and Research in Education, 8, 227247. 
Guimond, S. (2001). Epistemic authorities in higher education: The relative influence of peers, faculty and courses on attitude formation and change. In F.Butera \& G.Mugny (Eds.), Social influence in social reality (pp.211-223). Seattle: Hogrefe \& Huber.

Harjunen, E. (2009). How do teachers view their own pedagogical authority? Teachers and Teaching, 15(1), 109129.

Hepburn, A. (2006). Getting closer at a distance: theory and the contingencies of practice. Theory Psychology, $16,327-342$.

Heritage, J. \& Raymond, G. (2005). The terms of agreement: indexing epistemic authority and subordination in talk-in-interaction. Social Psychology Quarterly, 68(1), 15-38.

Jacobson, N. (2007). Social epistemology: Theory for the "fourth wave" of knowledge transfer and exchange research. Science Communication, 29, 116-127.

Jillapalli, K. R. \& Wilcox, B. J. (2010). Professor brand advocacy: Do brand relationships matter? Journal of Marketing Education, 32, 328-340.

Kruglanski, A. W. (1989). Lay epistemics and human knowledge: Cognitive and motivational bases. New York: Plenum.

Kruglanski, A. W., Raviv, A., Bar-Tal, D., Raviv, A., Sharvit, K., Ellis, S., Bar, R., Pierro, A. \& Mannetti, L. (2005). Says who?: Epistemic authority effects in social judgment. In M. P. Zanna (Ed.), Advances in Experimental Social Psychology, 37 (pp.346-392). San Diego: Elsevier Academic Press.

Mahrous, A. A., \& Ahmed Anis, A. (2010). A cross-cultural investigation of students' perceptions of the effectiveness of pedagogical tools: The Middle East, the United Kingdom, and the United States. Journal of Studies in International Education, 14, 289-306.

Miettinen, R., \& Virkkunen, J. (2005). Epistemic objects, artefacts and organizational change. Organization, 12, $437-456$.

Mugny, G., Chatard, A., Quiamzade, A. (2006). The social transmission of knowledge at the university: teaching style and epistemic dependence. European Journal of Psychology of Education, 21(4), 413-427.

Ordonez, G. X., Ponsoda, V., Abad, J. F. \& Romero, J. S. (2009). Measurement of epistemological beliefs: psychometric properties of the EQEBI test scores. Educational and Psychological Measurement, 69, 287-302.

Patchen, T. \& Crawford, T. (2011). From gardeners to tour guides: The epistemological struggle revealed in teacher-generated metaphors of teaching. Journal of Teacher Education, 62, 286-298.

Pounder, S. J. (2008). Full-range classroom leadership: Implications for the cross-organizational and crosscultural applicability of the transformational-transactional paradigm. Leadership, 4, 115-135.

Quiamzade, A., Mugny, G., Chatard, A. (2009). When teaching style matches students' epistemic (in) dependence: The moderating effect of perceived epistemic gap. European Journal of Psychology of Education, $X X I V(3), 361-371$.

Raviv, A., Bar-Tal, D., Raviv A., \& Abin, R. (1993). Measuring epistemic authority: studies of politicians and professors. European Journal of Personality, 7, 119-138.

Raviv, A., Bar-Tal, D., Raviv, A., Biran, B., \& Sela, Z. (2003). Teachers' epistemic authorities: perceptions of students and teachers. Social Psychology of Education, 6 (1), 17-42.

Raviv, A., Bar-Tal, D., Raviv, A., \& Peleg, D. (1990). Perception of epistemic authorities by children and adolescents. Journal of Youth and Adolescence, 19, 495-510.

Ricco, R., Schuyten Pierce, S., \& Medinilla, C. (2010). Epistemic beliefs and achievement motivation in early adolescence. The Journal of Early Adolescence, 30(2), 305-340. 
Rupp, E. D. (2011). An employee-centered model of organizational justice and social responsibility. Organizational Psychology Review, 1, 72-94.

Schommer-Aikins, M. (2004). Explaining the epistemological belief system: introducing the embedded systemic model and coordinated research approach. Educational Psychologist, 39(1), 19-29.

Subramaniam, B. (2010). Imperfect oracle: the epistemic and moral authority of science. contemporary sociology. A Journal of Reviews, 39(6), 687-688.

Ward, L., \& Parr, J. (2006). Authority, volunteerism, and sustainability: creating and sustaining an online community through teacher leadership. Leadership and Policy in Schools, 5(2), 109-129.

Docent Mg. psych. Solveiga Blumberga

Riga International School of Economics and Business Administration

$\mathrm{PhD}$ student of Daugavpils University

Address: Anniņmuižas str. 20-106, Riga, Latvia, LV-1029

Phone Mob.: +37126461229

E-mail: solveiga.blumberga@gmail.com 